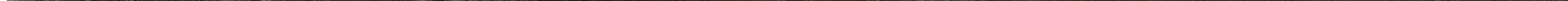




\title{
Un San Antonio de Padua con el Niño inédito de Sebastián Martínez Domedel en el museo del Monasterio de Poblet
}

\author{
An Unpublished Saint Anthony of Padua with the Child by Sebastián Martínez Domedel \\ in the Poblet Monastery Museum
}

\author{
Rafael Mantas Fernández \\ Universidad de Jaén, España \\ rmantas@ujaen.es \\ https://orcid.org/0000-0002-7365-8765
}

\author{
Damiá Amorós i Albareda \\ Museu del Monestir de Poblet, Espańa \\ museu@poblet.cat \\ https://orcid.org/0000-0002-7739-7822
}

\section{Resumen}

La creación de nuevos espacios expositivos de las instituciones museísticas o la mejora de sus instalaciones suponen una gran oportunidad para la realización de nuevos estudios de los inventarios y los catálogos de sus fondos artísticos. Así, las actividades de revisión y actualización de su información suelen arrojar nueva luz e interesantes novedades como la asignación de nuevas atribuciones sobre obras que hasta la fecha estaban catalogadas como anónimas. Gracias a la realización de estos trabajos, se ha ampliado el conocimiento en torno al lienzo de San Antonio de Padua con el Niño del museo del Real Monasterio de Poblet (Tarragona) al relacionar su autoría con el pintor Se-

\begin{abstract}
The creation of new exhibition spaces and the improvement of museum facilities represents a great opportunity for the realization of new studies regarding their art inventories and catalogs. In this way, the review and updating of existing information sheds new light on the works, including interesting developments such as the designation of works which until now were cataloged as anonymous. Thanks to the completion of these projects, knowledge surrounding the canvas Saint Anthony of Padua with the Child in the Real Monastery of Poblet Museum (Tarragona) has been extended, attributing its authorship to the painter Sebastián Martinez Domedel. Presented here
\end{abstract}

Cómo citar este trabajo / How to cite this paper:

Mantas Fernández, Rafael, y Damiá Amorós i Albareda. "Un San Antonio de Padua con el Niño inédito de Sebastián Martínez Domedel en el museo del Monasterio de Poblet." Atrio. Revista de Historia del Arte, no. 25 (2019): 44-57.

(C) 2019 Rafael Mantas Fernández y Damiá Amorós i Albareda. Este es un artículo de acceso abierto distribuido bajo los términos de la licencia Creative Commons Attribution-NonCommercial-ShareAlike 4.0. International License (CC BY-NC-SA 4.0). 
bastián Martínez Domedel. Se trata por tanto de la presentación de una obra inédita que se incorpora al catálogo de este artista del siglo XVII.

Palabras clave: Sebastián Martínez Domedel; Monasterio de Poblet; san Antonio de Padua; Barroco; pintura; inédito. is an unpublished work that is included in this XVII century artist's catalog.

Keywords: Sebastián Martínez Domedel; Monasterio de Poblet; saint Anthony of Padua; Baroque; painting; unpublished.

Introducción

El Real Monasterio de Poblet (Tarragona) es una abadía cisterciense edificada en el siglo XIII que alberga el panteón de los reyes de la Corona de Aragón. La singularidad y la magnificencia de su arquitectura al representar una obra maestra del genio creativo humano y el hecho de ser un ejemplo sobresaliente que ilustra una etapa significativa en la historia fueron los criterios reconocidos en 1991 por la Organización de las Naciones Unidas para la Educación, la Ciencia y la Cultura (UNESCO) para su declaración como uno de los ejemplos destacados del patrimonio mundial. ${ }^{1}$

Durante el periodo de 2017 y 2019 se está realizando la ampliación de su museo a través del proyecto Cosmos, con el que se pretende llevar a cabo la mejora integral del Real Monasterio de Poblet. Entre las acciones que se están ejecutando se encuentran la creación de un nuevo centro de visitantes y la nueva presentación de las salas del Palacio Real y de las salas Abat Copons y Abat Mengucho. Su finalidad es dotar al espacio de un nuevo discurso expositivo que versa sobre la vida monástica y su trascendencia religiosa. Gracias a estos trabajos, la colección permanente, que podrá ser visitada, se verá notablemente ampliada con la incorporación de un importante número de obras que hasta la fecha no habían sido presentadas públicamente. En consecuencia, se ha podido estudiar con mayor profundidad el patrimonio que forma parte de los fondos artísticos que acoge el monasterio cisterciense y su museo para revisar y actualizar las catalogaciones de su inventario. Actividades, que han sido posibles con el patrocinio y el respaldo institucional de la Generalitat de Catalunya, de la Diputació de Tarragona y de la comunidad cisterciense de Poblet.

Esta empresa se ha desarrollado especialmente en las colecciones de orfebrería, las cuales se han visto notablemente incrementadas, aunque en los últimos años también se ha realizado una importante labor en el conocimiento de la colección de escultura y pintura renacentista y barroca. Muestra destacada de ello son las nuevas catalogaciones en las esculturas de Damià Forment y Antoni Ramírez; mientras que las novedades correspondientes al período barroco son las telas recientemente atribuidas a Antoni Viladomat y la pieza inédita que centra este artículo.

\section{Descripción de la obra y estado de conservación}

En una de las estancias privadas de la comunidad, encontramos una gran tela $(176 \times 122 \mathrm{~cm})$ que representa el tema de San Antonio de Padua con el Niño, y que está inventariada con el número MPO 00058. El lienzo se encuentra reentelado y está enmarcado de forma muy austera con un sencillo marco de madera de pino. La pieza 
muestra una composición que economiza al máximo los recursos pictóricos expuestos. En el margen derecho se erige la figura del santo franciscano, y tras ella aparece un fondo neutro donde el artista solo representa el suelo embaldosado y una sobria pared sin ningún elemento decorativo. A pesar de las escasas referencias espaciales, estas sirven para ambientar la escena en un espacio interior. En el lado opuesto, se halla una mesa, cubierta por un mantel, donde se distribuye un bodegón compuesto por unos libros y un lirio. Encima del conjunto se deja ver la figura del Niño que acerca sus manos hacia San Antón, quien a pesar de estar sorprendido por la visión, describe un acto de complicidad para corresponderle al abrir sus brazos en busca del Divino Infante.

Su estado de conservación resulta extremadamente deficiente, por la amplia nómina de patologías que presenta: craquelados, desprendimientos y lagunas de la capa pictórica, pero sobre todo el envejecimiento de los barnices que han desvirtuado y oscurecido las tonalidades originales de unos pigmentos de formación terrosa. Con toda seguridad el aspecto actual de la pieza se debe a su exposición al humo y a las altas temperaturas de la combustión de unas velas, ya que debió estar expuesta en un oratorio destinado a la devoción de los fieles, tal y como era costumbre con la pintura de temática religiosa. Por este motivo, la obra presenta un color apagado y en algunas partes la tela se encuentra destensada, a pesar de que está reentelada. Es por ello que resultaría urgente realizar una profunda intervención para poder salvar el cuadro.

Sobre el emplazamiento original de la pieza y su llegada al Monasterio de Poblet tenemos poco conocimiento al respecto, al no disponer de noticias. Al estar reentelada a un nuevo lienzo, no podemos saber si en la parte posterior aparecen marcas o símbolos identificativos. Podemos deducir que la obra llegó a Poblet después de 1940, cuando vuelve el cenobio a la vida monástica, y muy probablemente como depósito de la Junta de Incautación y Protección del Patrimonio Histórico.

\section{Aproximación a la iconografía de san Antonio de Padua}

San Antonio de Padua fue junto a San Francisco de Asís uno de los santos seráficos que tuvo una mayor popularidad, debido a la amplia nómina de milagros acaecidos a lo largo de su vida, siendo por este motivo conocido en Italia y en Espańa como Il Taumaturgo o El Milagrero. ${ }^{2}$ Algunos de los prodigios que se le atribuyen son la predicación a los peces, la curación de la pierna cortada a un joven o la mula arrodillada ante una custodia, pero sobre todo, el suceso más destacado en torno a su figura, es el privilegio de ser testigo de una visión mística en la que se le apareció el Niño Jesús cuando se encontraba orando en una habitación durante su estancia en Francia. La enorme popularidad que adquirió la representación iconográfica de este episodio de la vida de este santo natural de Lisboa, es quizás la más importante, tal y como refleja el significativo número de obras que reproducen este tema a lo largo de la Historia del Arte, que resulta especialmente concentrado en la pintura barroca hispánica y flamenca de la Contrarreforma. ${ }^{3}$

Precisamente, esta temática, narrada en el Liber Miracolorum, gozó de gran difusión en el mercado del arte español durante todo el siglo XVII y bien entrado el XVIII. Así, las principales escuelas peninsulares del Siglo de Oro — la sevillana, la madrileña y también la valenciana — asumieron el pasaje hagiográfico de

2. Louis Réau, Iconografía del Arte cristiano (Barcelona: Ediciones del Serval, 1996), t. 2, vol. 3, 124.

3. Réau, 130 


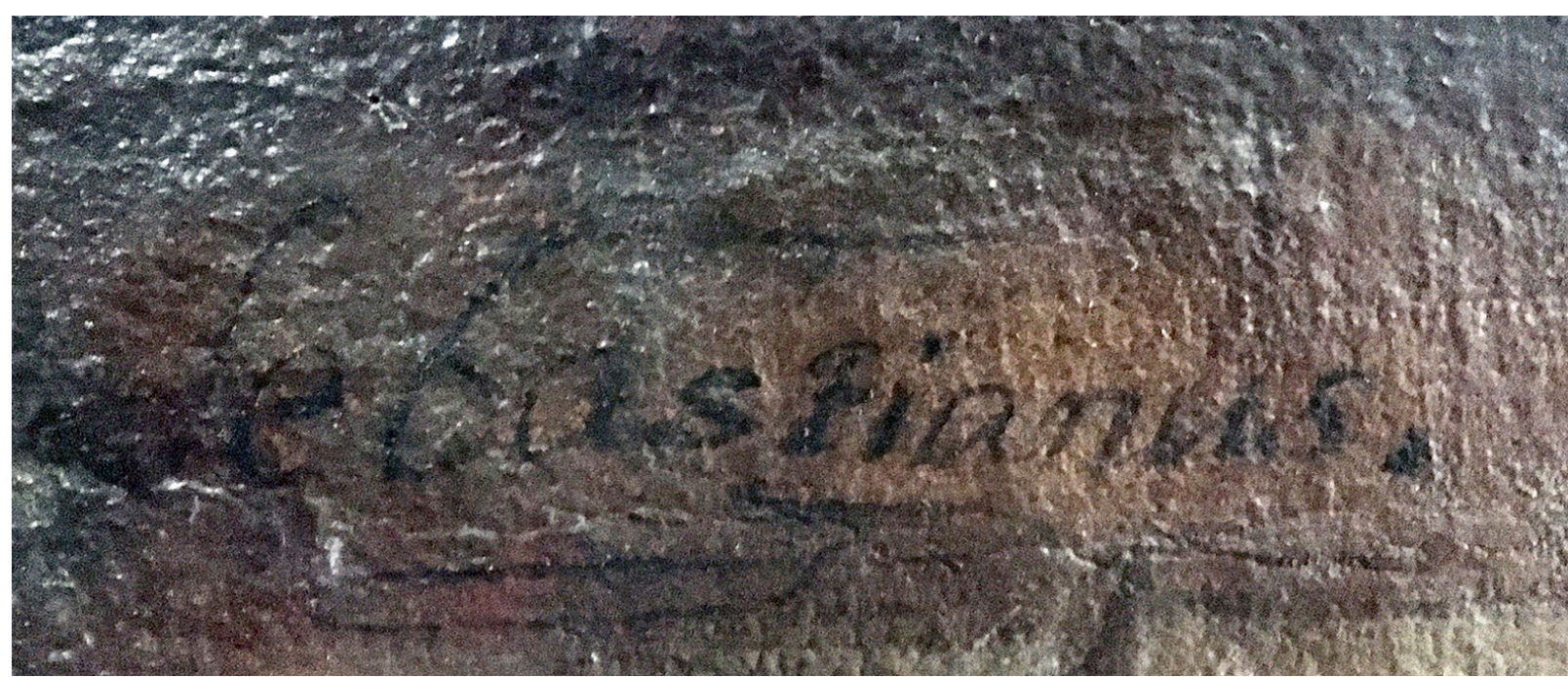

Fig. 2. Sebastián Martínez Domedel, San Antonio de Padua con el Niño (Detalle de la firma), hacia 1640-1650. Óleo sobre lienzo, $176 \times 122 \mathrm{~cm}$. Museo de Poblet, Tarragona. (Fotografía de los autores).

la aparición del Niño Jesús a san Antonio de Padua ${ }^{4}$ como uno de sus temas referenciales, seguramente por la buena aceptación que tuvo entre los comitentes de espiritualidad franciscana, por crear una iconografía influenciada por la meditación que hizo Pseudo Buenaventura sobre el Divino Infante en el pesebre de Belén. ${ }^{5}$ Es por ello, que encontramos piezas atribuidas a los grandes nombres de la pintura barroca como Murillo, Zurbarán, Valdés Leal, Juan Carreño de Miranda, Claudio Coello, Alonso Cano, Herrera el joven o Antonio del Castillo.

La iconografía de este episodio presenta diversas variantes sobre la aparición mística que tuvo san Antonio de Padua, pues generalmente el Niño Jesús se personifica solo ante el santo franciscano; mientras que en otras ocasiones suele ser entregado por la Virgen, como sucede en la Visión de San Antonio de Padua de Alonso Cano de la Alte Pinakothek de Munich. La creación del museo del Monasterio de Poblet, representa el momento preciso de la aparición del Divino Infante en un espacio interior, a diferencia de otras donde el entorno es exterior o un fondo celestial. El fondo, con tonalidades terrosas, pero menos oscuras que el hábito franciscano del santo, contrasta con la mantelería de la mesa y la túnica roja del Niño, que con toda seguridad después de una buena restauración luciría con un cromatismo mucho más vivo que el actual. Un atuendo que se precisa necesario para salvaguardar el decoro de la escena, según la crítica de Interián de Ayala de pintar "contra la fé del Evangelio, totalmente desnudo al Divino Niño en el pesebre (...) practiquen lo mismo con S. Antonio, lo que ya (...) hemos hecho vér quan ageno es de la gravedad, y modestia Christiana."

Debajo del Niño, se localizan otros atributos iconográficos de San Antonio: ${ }^{7}$ una rama de lirio en flor, que simboliza la pureza del santo, y unos libros que se corresponden con las Sagradas Escrituras, los cua-

4. Claudio Leonardi, Andrea Riccardi, y Gabriella Zarri, Diccionario de los Santos (Madrid: San Pablo, 2000), 1:235-39.

5. José Joaquín Quesada Quesada, "Iconografía Franciscana en la provincia de Jaén. Del siglo XIII a la Desamortización de 1836" (tesis doctoral, Universidad de Jaén, 2017), 371-72.

6. Juan Interián de Ayala, El pintor christiano, y erudito, ó Tratado de los errores que suelen cometerse freqüentemente en pintar, y esculpir las Imágenes Sagradas (Madrid: Joachín Ibarra, 1782), 362-63.

7. Réau, Iconografía del Arte cristiano, t. 2, vol. 3, 127. 

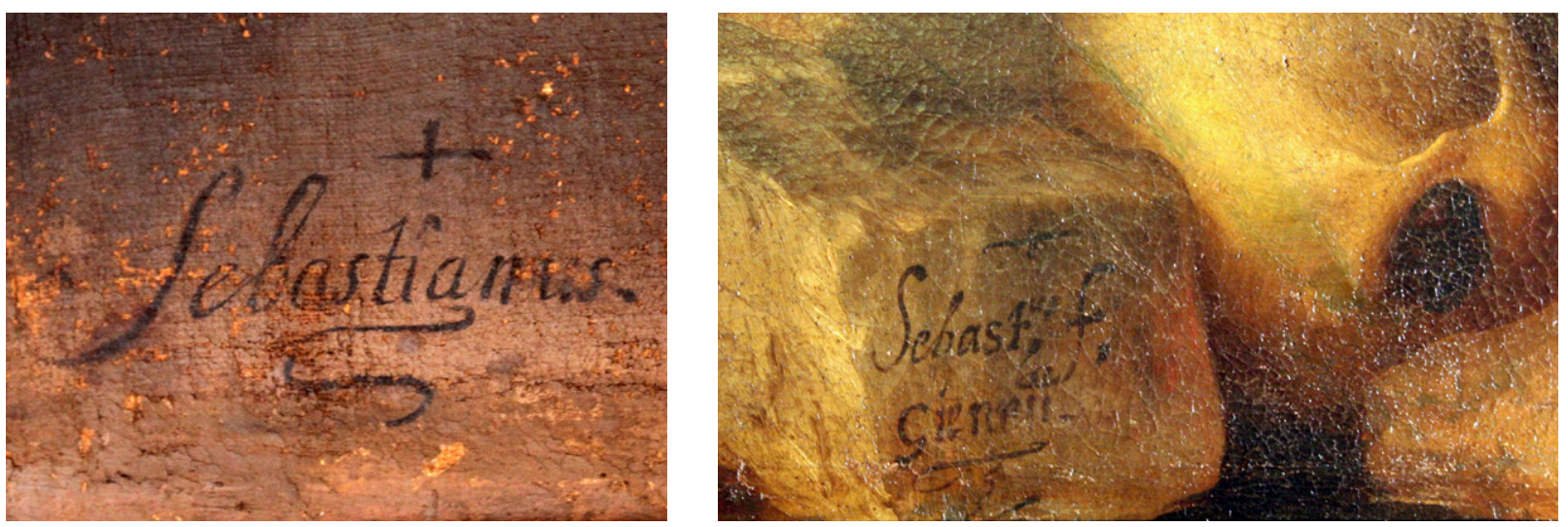

Fig. 3. Sebastián Martínez Domedel, San Pedro (Detalle de la firma), hacia 1650. Óleo sobre lienzo, $203 \times 137 \mathrm{~cm}$. Palacio Episcopal, Córdoba. Sebastián Martínez Domedel, Crucificado (Detalle de la firma), hacia 1660-1665. Óleo sobre lienzo, 320 × $230 \mathrm{~cm}$. Exposición Permanente de Arte Sacro, S. I. Catedral de Jaén. (Fotografías de los autores).

les acreditan al santo lisboeta como una persona erudita y docta de gran formación, por lo que san Antonio de Padua fue nombrado como Doctor de la Iglesia en 1946 por Pío XII. ${ }^{8}$ Este conjunto representa una buena muestra del conocimiento de la naturaleza muerta, afín al naturalismo desarrollado durante la segunda mitad del siglo XVII en la pintura hispánica y especialmente en la escuela andaluza.

\section{Autoría del cuadro}

El mal estado de conservación en el que se encuentra la pieza ha ocultado las tonalidades originales de los pigmentos, desvirtuando su concepción original y dificultando el estudio de las pinceladas, así como de otros aspectos relacionados con su técnica, haciendo por tanto extremadamente confuso el hecho de precisar una atribución. Sin embargo, gracias a la realización de un análisis en profundidad del conjunto, pero sobre todo el hallazgo de la firma "Sebastianus" ha sido la clave para realizar una posible atribución sobre el cuadro a Sebastián Martínez Domedel (Jaén, c. 1615-Madrid,1667). ${ }^{9}$ Anteriormente, esa misma grafía vinculada con este pintor giennense del siglo XVII también fue encontrada en el San Pedro y el Santiago el Mayor del Apostolado del Palacio Episcopal de Córdoba ${ }^{10}$ y recientemente parte de ella ha sido localizada en uno de los santos jesuitas San Ignacio de Loyola y San Francisco Javier de la iglesia del Sagrado Corazón de Granada, procedentes del santuario del Santo Cristo de Burgos de Cabra de Santo Cristo (Jaén). En este último caso su descubrimiento ha sido determinante para corroborar su autoría. ${ }^{11}$

8. James Hall, Diccionario de temas y símbolos artísticos (Madrid: Alianza, 1987), 39.

9. Rafael Galiano Puy, "Catálogo de artistas y artesanos de la ciudad de Jaén (1634-1684) de Juan de Aranda Salazar a Eufrasio López Rojas (II)," Boletín de Estudios Giennenses, no. 205 (2012): 107-8

10. José María Palencia Cerezo, "Sebastián Martínez y el Apostolado del Palacio Episcopal de Córdoba," en Actas del Congreso Internacional Andalucía Barroca (Antequera, 17-21 de septiembre de 2007), coord. Alfredo J. Morales (Sevilla: Consejería de Cultura de la Junta de Andalucía, 2009 ), $373-84$.

11. Los lienzos fueron atribuidos a Sebastián Martínez por Benito Navarrete Prieto, "Sebastián Martínez, nueva luz sobre su obra" (conferencia, Diputación Provincial de Jaén, Jaén, 27 de mayo de 2010), y posteriormente recogidos en Benito Navarrete Prieto, "Sebastián Martínez Domedel en el contexto de la pintura barroca andaluza," en Sebastianus. Pintor de Jaén. Sebastián Martínez Domedel (Jaén, 1615-Madrid, 1667), coords. Pedro A. Galera Andreu y Felipe Serrano Estrella (Jaén: Diputación Provincial de Jaén e Instituto de Estudios Giennenses, 2016), 38-41. El profesor León Coloma ha estudiado las fuentes iconográficas de estos santos jesuitas y ha verificado esta hipótesis al localizar parte de la firma "S[...]a[...]" en el lienzo de San Francisco Javier. Véase Miguel Ángel León Coloma, "Iconografía Barroca de San Ignacio de Loyola y San Francisco Javier. Notas a una exposición," en La huella de los jesuitas en Granada. Del colegio de San Pablo a la Facultad de Teología, dir. Francisco Javier Martínez Medina (Granada: Facultad de Teología, 2014), 153-208. 
En efecto "Sebastianus" era la firma común tal y como se observa en gran parte de las obras documentadas que forman su catálogo, ${ }^{12}$ si bien esta no es la única ya que también solía utilizar la rúbrica "Sebastus f. giennii." ${ }^{13}$ Ambas proporcionan una interesante información sobre el pintor al mostrar el nombre del artista escrito en latín, siendo este un acto consciente por su parte para remarcar su intelectualidad y para buscar el reconocimiento público y social, del mismo modo que lo hicieron otros compañeros de profesión. Asimismo, en la segunda de las firmas incorpora su gentilicio como signo de identificación con su ciudad natal para indicar sus orígenes, al igual que Ribera, quien solía acompañar su firma con las grafías "español" o "hispanus". Por otro lado, estas rubricas cuestionan la veracidad de una anécdota relatada por Antonio Palomino en su Museo pictórico y escala óptica al afirmar que el pintor giennense firmaba sus obras como "Martínez fecit" a raíz de un amistoso encuentro con Felipe IV. ${ }^{14}$ Pese a la existencia de este testimonio no ha sido posible localizar ningún lienzo con dicha grafía.

A pesar de que durante mucho tiempo la crítica no le ha prestado mucha atención a Sebastián Martínez Domedel, actualmente es considerado el máximo representante de la pintura barroca giennense y según señalaron Pérez Sánchez y Navarrete Prieto se trata de una figura "fundamental para perfilar el importante foco pictórico que se desarrolla en Jaén, Córdoba y Granada en el segundo tercio del siglo XVII."15

Martínez Domedel es un autor con un corpus creativo de calidad, aumentado en las últimas décadas por las investigaciones que han sacado a la luz obras inéditas y por las propuestas de nuevas atribuciones alrededor de su pincel y taller. ${ }^{16}$ Un ejemplo de este redescubrimiento fue la muestra Sebastianus, pintor de Jaén, celebrada en la catedral de Jaén durante el año 2016, que sirvió para presentar públicamente los cuadros de los Evangelistas de la catedral de Jaén tras ser restaurados. Igualmente, las adquisiciones de sus obras por parte de instituciones museísticas son otra forma para calibrar esta realidad, tal y como demuestra la Santa Catalina $^{17}$ y el San Juan Bautista ${ }^{18}$ del Museo Provincial de Jaén o el San José con el Niño del Museo Nacional del Prado. ${ }^{19}$ Esta dinámica ascendente también se observa en la presencia de interesantes telas en importantes ferias de arte como TEFAF Maastricht, tal y como ha ocurrido en las ediciones de 2017 y 2018, con una Inmaculada Concepción de la galería Caylus de Madrid ${ }^{20}$ y con el San Juanito o Agnus Dei del anticuario de Barcelona, Artur Ramon Art. ${ }^{21}$

12. Algunas de las obras que poseen esa misma rúbrica son el Martirio de San Sebastián de la catedral de Jaén, la Santa Catalina y el San Juan Bautista del Museo Provincial de Jaén; el San Francisco de Asís, el San Jerónimo y la Inmaculada Concepción del convento de Santa María de Gracia de Córdoba y la Santa Águeda o el San Antonio Abad y San Pablo ermitaño de la colección Granados.

13. Encontramos esa firma en el Crucificado de la catedral de Jaén y el San José con el Niño del Museo Nacional del Prado.

14. La anécdota descrita por Palomino entre Sebastián Martínez Domedel y Felipe IV es la siguiente: "y sucedió, que pintando un día en Palacio, y estando sentado, llegó el Rey por detrás, cogiéndole descuidado; y habiéndose él conocido a su Majestad, levantábase para hacer el debido acatamiento; y entonces el Rey le puso las manos sobre los hombros diciéndole: Estáte quedo Martínez; y él desde entonces, venerando esta honra, acostumbró a poner en sus obras: Martínez fecit, que antes ponía su nombre entero." Véase Antonio Palomino de Castro y Velasco, Museo pictórico y escala óptica (Madrid: Aguilar, 1947$), 948$.

15. Benito Navarrete Prieto y Alfonso E. Pérez Sánchez, Álbum Alcubierre. Dibujos. De la Sevilla llustrada del Conde del Águila a la Colección Juan Abelló (Madrid: Fundación Arte Hispánico, 2009), 249.

16. Véanse los trabajos recogidos en la bibliografía de Rafael Cañada Quesada, Manuel Capel Margarito, Pedro A. Galera Andreu, Ma Soledad Lázaro Damas, Miguel Ángel León Coloma, Rafael Mantas Fernández, Benito Navarrete Prieto, José María Palencia Cerezo y Felipe Serrano Estrella.

17. Propuesta de adquisición en subasta de la obra "Santa Catalina" de Sebastián Martínez. 5.1.1.3. Depósito no estatal. "Santa Catalina" de Sebastián Martínez. BA768. 2005

18. Propuesta de adquisición en subasta de la obra "San Juan Bautista" de Sebastián Martínez. 5.1.1.3. Depósito no estatal. "San Juan Bautista" de Sebastián Martínez. BA779. 2006

19. Javier Portús, "Sebastián Martínez (h. 1615-1667). San José con el Niño (hacia 1650)," en Memoria de actividades 2009 (Madrid: Museo Nacional del Prado, 2010), 26-28.

20. La atribución de este lienzo fue defendida públicamente por Navarrete Prieto, "Sebastián Martínez, nueva luz." Y ha sido recogida en Navarrete Prieto, "Sebastián Martínez Domedel en el contexto," 54-58.

21. La atribución de este lienzo de Artur Ramon Art ha sido publicada en Navarrete Prieto, "Sebastián Martínez Domedel," 17-57. José María Palencia Cerezo también confirma la atribución en Artur Ramon Art, "Sebastián Martínez Domedel. Agnus Dei," consultado el 19 de febrero de 2019

https://www.arturamon.com/fira/tefaf-maastricht-2/1-sebstian-martinez-domadel/ 

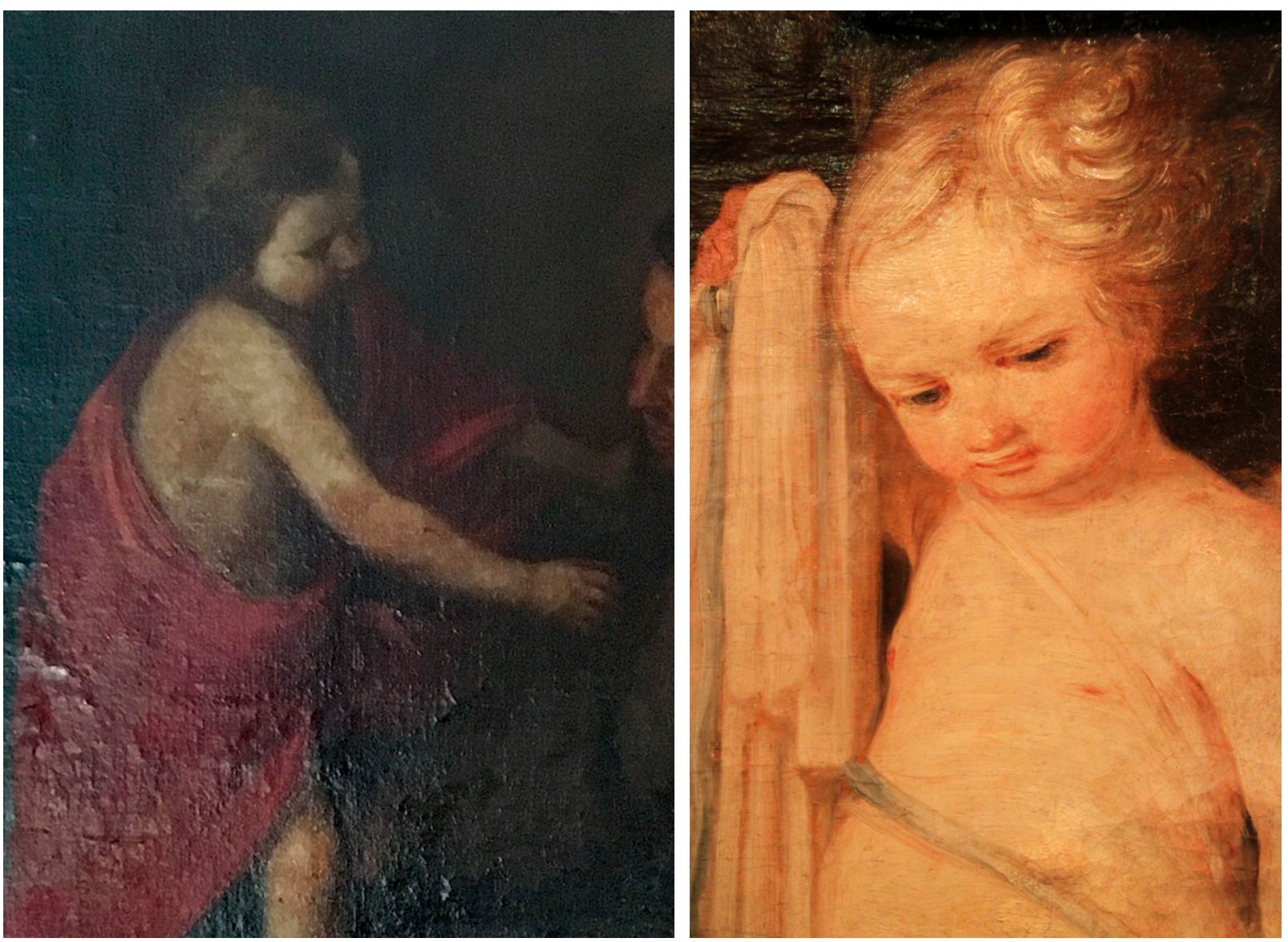

Fig. 4. Sebastián Martínez Domedel, San Antonio de Padua con el Niño (Detalle Niño Jesús), hacia 1640-1650. Óleo sobre lienzo. $176 \times 122$ cm. Museo de Poblet, Tarragona. Sebastián Martínez Domedel, Santo Rostro sostenido por ángeles (Detalle ángel), 1660. Óleo sobre tela adherido a una tabla, 90,5 × 94,5 cm. S. I. Catedral de Jaén. (Fotografías de los autores).

Resulta, en estos momentos, aún más interesante descubrir nuevas contribuciones al catálogo de un pintor del siglo XVII puesto en valor en las últimas décadas. El lienzo pobletano aumenta el corpus temático e iconográfico de Sebastián Martínez. San Antonio de Padua con el Niño, plantea una nueva aportación, pero con la repetición de algunos de los recursos técnicos y modelos ya conocidos del pintor giennense.

Además de la firma, podemos argumentar la atribución con la relación de recursos iconográficos y técnicos recurrentes en la obra de Martínez Domedel. Una pieza muy próxima en su temática al cuadro de Poblet es el San Francisco recibiendo la ampolla, ${ }^{22}$ de $205 \times 107 \mathrm{~cm}$, del Colegio Alberoni de Piacenza (Italia). Ambos lienzos representan a santos franciscanos contemplando ensimismados una revelación mística. En el lienzo italiano San Francisco recibe una redoma de agua de manos de un ángel, mientras que en la versión pobletana San Antonio presencia la aparición del Niño Jesús. La composición de ambos personajes es similar, sobre todo en los expresivos gestos de las manos abiertas. Además, en las dos telas encontramos una mesa cubierta con un mantel sobre la que se disponen diversos bodegones, cuya inclusión sirve para equilibrar la 

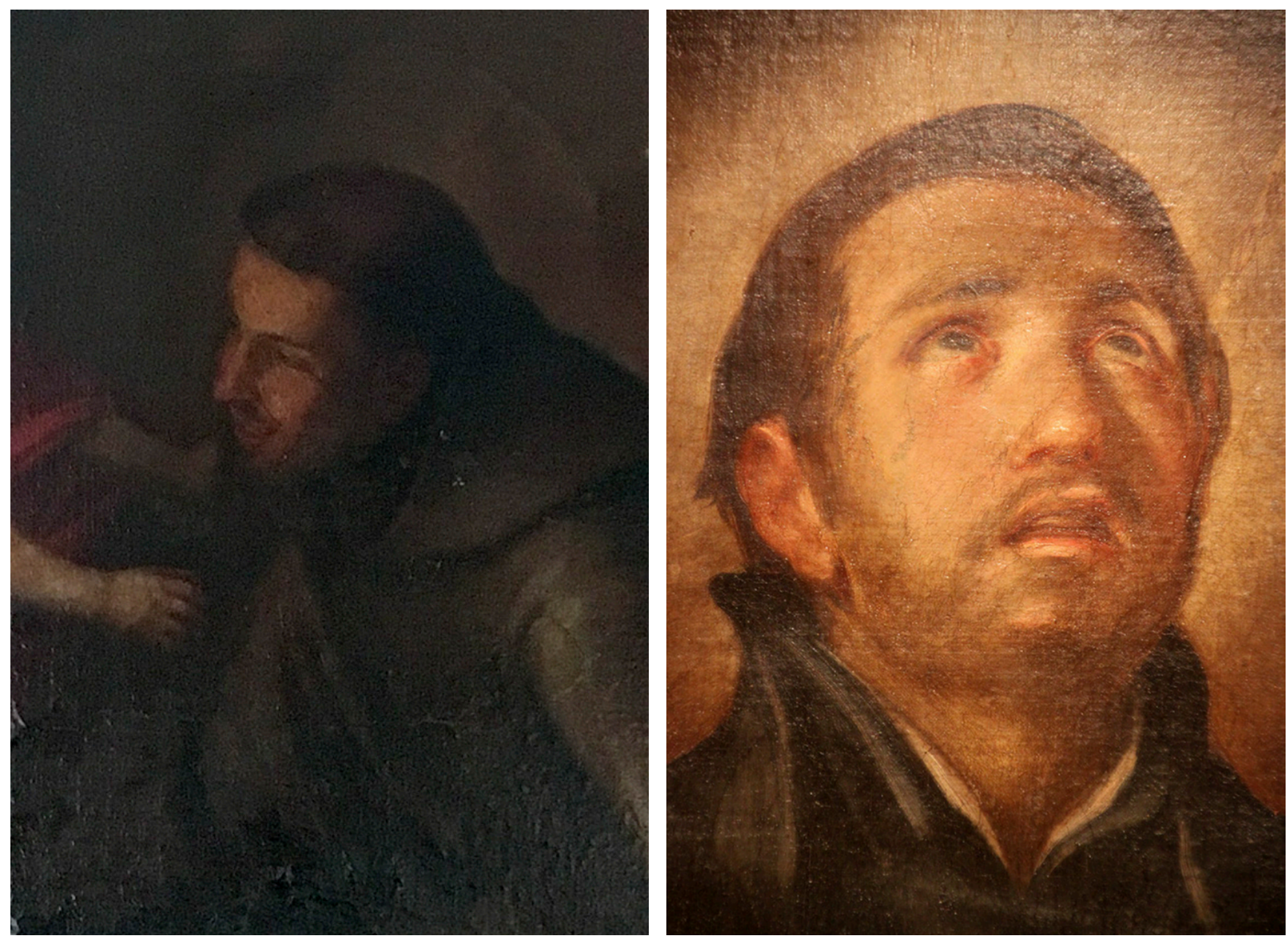

Fig. 5. Sebastián Martínez Domedel, San Antonio de Padua con el Niño (Detalle del rostro del santo), hacia 1640-1650. Óleo sobre lienzo 176 × $122 \mathrm{~cm}$. Museo de Poblet, Tarragona. Sebastián Martínez Domedel, San Francisco Javier (Detalle del rostro del santo), hacia 1650-1655. Óleo sobre lienzo, $190 \times 120 \mathrm{~cm}$. Iglesia del Sagrado Corazón de Granada. (Fotografías de los autores).

composición y como pretexto para mostrar unos buenos ejemplos de pintura naturalista. Asimismo se observa que los dos cuadros presentan un registro cromático similar, al estar trabajados con una paleta reducida en la que predominan los colores tierra, principalmente ocres. Por otro lado, el lienzo de Poblet también podríamos relacionarlo con la versión de San Francisco recibiendo la redoma del convento de Santa María de Gracia de Córdoba que reproduce el mismo tema que la tela italiana, aunque en esta ocasión la escena está ambientada en un rocoso espacio exterior. Según señaló Antonio Palomino, este cuadro anteriormente perteneció al convento dominico del Corpus Christi de la misma ciudad, al mismo tiempo que comunicaba que formaba parte de una serie que estaba compuesta por una Inmaculada, un San Jerónimo y una Adoración de los pastores, destacando su calidad al calificarlos como una "cosa excelente" dado que "todos muestran bastantemente la eminencia, y capricho de su autor." 23

Por su parte, el Niño también resulta un personaje recurrente en la obra del pintor de Jaén, tanto por la técnica empleada como por el modelo iconográfico que presenta. Dentro de la producción del autor, las 
figuras infantiles rentabilizan un esquema muy similar entre ellas, sobretodo en el tratamiento del peinado. Así, las diversas representaciones de los Ángeles y del Niño Jesús que aparecen en repetidas telas muestran airadas y onduladas cabelleras. Nos podemos remitir a los modelos de la puerta del relicario del Santo Rostro de Jaén, ${ }^{24}$ al San Juanito de Artur Ramon Art o al acompańamiento celestial del Martirio de San Crispin y San Crispiniano del Palacio Episcopal de Jaén. ${ }^{25}$

La figura de san Antonio de Padua también evoca a otros modelos utilizados por Martínez Domedel en piezas ya conocidas de su producción y aceptadas por los especialistas. Hasta el momento, la única representación de san Antonio de Padua en la obra del pintor giennense, se encuentra en un dibujo que se le atribuye, titulado Virgen y santos adorando a la Santísima Trinidad que forma parte del Álbum Alcubierre. ${ }^{26}$ Debió tratarse de un estudio previo para una obra posterior ${ }^{27}$ en el que aparecen los santos mercedarios en compañía de la Virgen titular de la orden siendo bendecidos por Dios Padre, Hijo y Espíritu Santo y algunos miembros de la orden franciscana, entre los que se encuentra san Antonio de Padua, pero presenta ligeras diferencias si lo comparamos con el del lienzo del Monasterio de Poblet.

Para la caracterización física del santo, Sebastián Martínez opta por representar a una persona de edad juvenil y de aspecto imberbe que puede tener ligeras reminiscencias con el San Francisco Javier de la iglesia del Sagrado Corazón de Granada, con el San Sebastián del cuadro que narra su martirio en la catedral de Jaén e incluso con el San Juan Evangelista que forma parte de la serie de Evangelistas del templo mayor giennense. Sin embargo, esta personalización será posteriormente censurada por Interián de Ayala al argumentar que el santo murió cerca de los 40 años y que a esa edad ya era "verdaderamente varonil: á mas de que, fatigado por los muchos trabajos de su predicacion, y casi extenuado por los ayunos, y áspera penitencia, no es conforme á razon que se le pinte mozo." 28

De su figura sobre todo destaca la emotiva y tímida sonrisa que esboza en su rostro mientras busca la complicidad del abrazo del Nińo Jesús. El gesto de sorpresa y la expresiva disposición de su figura tienen un planteamiento próximo al que Sebastián Martínez Domedel muestra en el dibujo San Francisco recibiendo los privilegios de la orden franciscana de la Kunsthalle de Hamburgo, uno de los pocos estudios sobre el que se conoce con certeza la autoría del pintor giennense. ${ }^{29}$ Asimismo, existen ciertas relaciones en el modo de definir los hábitos de ambos santos, donde aparecen representados los característicos pliegues marcados y pesados que realiza el pintor giennense para dotar a sus personajes de una corporeidad escultórica.

Para configurar esta escena de la vida de San Antonio parece ser que Sebastián Martínez Domedel recurrió a una estampa homónima de Simone Cantarini (1612-1648), ${ }^{30}$ pues existen fuertes concomitancias

\footnotetext{
24. Felipe Serrano Estrella, coord., Cien obras maestras de la Catedral de Jaén (Jaén: Universidad de Jaén y Cabildo de la S. I. Catedral de Jaén, 2012 ), 174-77.

25. Rafael Mantas Fernández, "Claves estilísticas y formales en torno a la paleta de Sebastian Martínez," en Barroco Iberoamericano: identidades culturales de un Imperio, coords. Carme López Calderón, María de los Ángeles Fernández Valle, y María Inmaculada Rodríguez Moya (Santiago de Compostela: Andavira, 2013), 393.

26. El Álbum Alcubierre perteneció a Miguel de Espinosa Maldonado (1715-1784), quien fuera Il Conde del Águila. Véase Navarrete Prieto y Pérez Sánchez, Álbum Alcubierre, 144-45.

27. La obra tuvo que ser encargada para un convento de religiosos mercedarios, con la intención de destacar los valores de la orden de la Merced, al glorificar su fundación y recordar el vínculo de sus votos con los franciscanos.

28. Interián de Ayala, El pintor christiano, y erudito, 363.

29. Este dibujo está realizado con pluma y aguada, tinta parda y sanguina sobre pergamino (220 x $167 \mathrm{~mm})$ y en la parte inferior posee la firma "Sebastian martinez". Como aspecto anecdótico, anteriormente perteneció a la colección de Juan Agustín Ceán Bermúdez. Véase Jens Hoffmann-Samland, coord., Dibujos españoles en la Kunsthalle de Hamburgo (Madrid: Museo Nacional del Prado, 2014), 68-69.

30. Adam Von Bartsch, The Illustrated Bartsch (New York: Abaris Books, 1978), 42:97-98.
} 
entre ambas obras. La producción de este artista italiano, que fuera discípulo de Guido Reni, fue especialmente conocida entre los pintores andaluces del siglo XVII por la sensibilidad, intimidad y delicadeza con la que solía abordar los temas de carácter devocional. Precisamente, la influencia de este grabado que narra la visión mística del santo seráfico tuvo una importante difusión, tal y como se detecta, entre otros, en la versión de Bartolomé Esteban Murillo del Museo del Ermitage ${ }^{31}$ o en la planteada por Juan de Valdés Leal del Museo de Bellas Artes de Valencia. ${ }^{32}$

En concreto, el lienzo del Monasterio de Poblet reproduce la composición en diagonal planteada por Simone Cantarini, sin embargo lo hace de forma simplificada, ya que Sebastián Martínez Domedel únicamente centra su atención en las figuras de San Antonio y el Nińo, eliminando para ello a todos los ángeles del rompimiento de cielo que completan la escena en la versión italiana. De esta forma muestra una composición sencilla que resulta muy efectiva desde el punto de vista religioso para incitar a la oración y a la piedad del fiel. Se trata por tanto de la elección del momento de mayor tensión emocional de la escena, siendo este un aspecto que suele ser frecuente en la producción de Sebastián Martínez, aunque en esta ocasión lo hace de una forma mucho más amable que la desarrollada en el San Antonio Abad y San Pablo ermitaño de la colección Granados o en el Crucificado de la catedral de Jaén.

Otro elemento inequívoco del cuadro de San Antonio de Padua y el Niño es que posee el sello del giennense en el excelente estudio de los libros, cuyos ejemplos están en la misma línea a los que aparecen en los lienzos de los Evangelistas de la catedral de Jaén. Además de ello, destaca el naturalismo de los lirios, los cuales son definidos con gran veracidad, dado que Sebastián Martínez demuestra ser un gran pintor de flores como sucede en las diferentes versiones de sus Inmaculadas o en la Santa Águeda de la colección Granados.

El empleo del fondo neutro con fuertes contrastes lumínicos a través de un haz de luz entrecortado también es un elemento característico en el estilo de Sebastián Martínez, tal y como podemos ver en el Apostolado del Palacio Episcopal de Córdoba, el San José con el Niño del Museo del Prado o el San Francisco del Colegio Alberoni de Piacenza. Al igual que sucede en las obras referidas, el cuadro de Poblet describe un contexto en penumbra que agudiza la tensión emocional de la escena, que ha sido lograda gracias al uso de unos pigmentos terrosos para la preparación de la base del lienzo.

La datación de la obra resulta compleja, pues a pesar de que en los últimos años se está perfilando el catálogo de Martínez Domedel, este todavía sigue siendo reducido, dado que tan solo sabemos con precisión la fecha de ejecución de unos pocos lienzos, todos ellos datados entre 1660 y 1667, coincidiendo con la época más prolífica de su producción cuando desempeñó importantes y variados encargos para la catedral de Jaén y alternó su estancia y sus trabajos entre su ciudad natal y Madrid, donde Antonio Palomino lo sitúa en la Corte de Felipe IV. ${ }^{33}$ En este momento se fechan entre otros El Santo Rostro sostenido por ángeles (1660) y el Martirio de San Sebastián (1663) de la catedral giennense y la Santa Águeda (1660-1667) $)^{34}$ de la colección Granados.

31. Benito Navarrete Prieto, La pintura andaluza del siglo XVII y sus fuentes grabadas (Madrid: Gráficas Caro, 1998), 293.

32. Enrique Valdivieso, Valdés Leal (Sevilla: Ediciones Guadalquivir, 1988), 142.

33. Palomino de Castro y Velasco, Museo pictórico, 948.

34. Posee la inscripción "Sebastianus Cordoba en 166[...]" en el ángulo inferior derecho y la dedicatoria "Sr D. Luis Gomez ft [...] Figueroa" en el ángulo inferior izquierdo. Véase Mindy Nancarrow y Benito Navarrete Prieto, Antonio del Castillo (Madrid: Fundación de Apoyo a la Historia del Arte Hispánico, 2004), 111; José María Palencia Cerezo y Javier Del Campo, El esplendor del Barroco Andaluz. Colección Granados (Córdoba: Imprenta San Pablo, 2007), 156-57; José María Palencia Cerezo y Javier Del Campo, Espíritu Barroco. Colección Granados (Burgos: Caja de Burgos, 2008), $164-65$. 

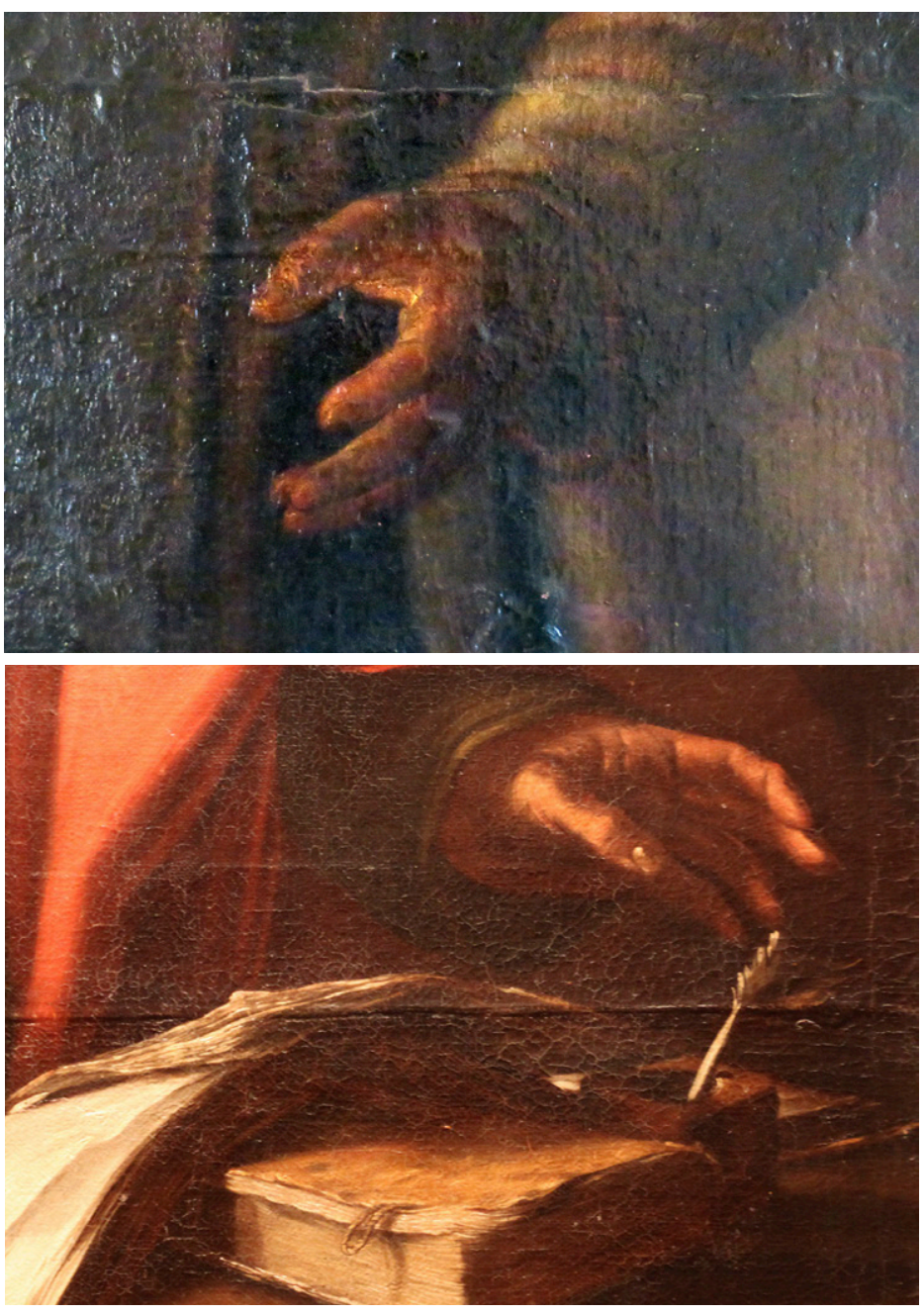

Fig. 6. Sebastián Martínez Domedel, San Antonio de Padua con el Niño (Detalle de la mano del santo), hacia 1640-1650. Óleo sobre lienzo, $176 \times 122 \mathrm{~cm}$. Museo de Poblet, Tarragona. Sebastián Martínez Domedel, San Juan Evangelista (Detalle de la mano del santo), hacia 1655. Óleo sobre lienzo, $213 \times 143 \mathrm{~cm}$. S. I. Catedral de Jaén.

(Fotografías de los autores).
hizo más "anieblado" pictórico y escala óptica, su estilo se No obstante, durante ese período su pintura ya debía gozar de un gran prestigio en la ciudad de Jaén, donde consolidaba su obrador como uno de los más afamados del ámbito local y provincial. Dentro de este contexto se produce la solicitud de Francisco Santo para ser aprendiz de Sebastián Martínez, a quien la documentación lo citaba como "maestro ynsigne en el dho arte." ${ }^{39}$ Finalmente, el 21 de marzo de 1640, este joven y desco-

\footnotetext{
35. Mercedes Agulló y Cobo, Noticias sobre pintores madrileños de los siglos XVI y XVII (Granada: Departamento de Historia del Arte de la Universidad de Granada, Madrid: Departamento de Historia del Arte de la Universidad Autónoma de Madrid, 1978), 94.

36. Archivo Histórico de Protocolos de Madrid (AHPM), Protocolos Notariales, Carta de pago otorgada a Sebastián Martínez, 3 de marzo de 1662, legajo 9432, $184 \mathrm{r}-184 \mathrm{v}$.

37. Portús, "Sebastián Martínez," 26-28.

38. Palomino de Castro y Velasco, Museo pictórico, 948

39. Archivo Histórico de Protocolos, Jaén (en adelante AHPJ): Protocolos Notariales, Petición de Francisco Santo para ser aprendiz de Sebastián Martínez, 16 de enero de 1640, legajo 1513, 128v-129v. Véase María Soledad Lázaro Damas, "Consideraciones en torno a Sebastián Martínez Domedel y su obra," Boletín del Instituto de Estudios Giennenses 1, no. 153 (1994): 304-5.
} 
nocido pintor, que hasta el momento figura como su único discípulo documentado, accedió al taller por un tiempo estimado de seis años, en el que Sebastián Martínez Domedel se obligaba a enseñarle al menor "todo lo que yo pudiere enseñarle y el de aprender." ${ }^{30}$

Con toda seguridad nos encontramos con la primera obra conocida de Sebastián Martínez Domedel dedicada a San Antonio de Padua y el Niño. Una pieza totalmente inédita conservada en el museo del Real Monasterio de Poblet que se incorpora al catálogo de este pintor giennense del Seiscientos gracias a las diversas labores de catalogación llevadas a cabo por los profesionales de dicha institución y por al trabajo de investigación del presente artículo.

\section{Referencias}

Agulló y Cobo, Mercedes. Noticias sobre pintores madrileños de los siglos XVI y XVII. Granada: Departamento de Historia del Arte de la Universidad de Granada, Madrid: Departamento de Historia del Arte de la Universidad Autónoma de Madrid, 1978.

Bartsch, Adam Von. The Illustrated Bartsch. New York: Abaris Books, 1978.

Cañada Quesada, Rafael. "Nuevas noticias sobre el giennense Sebastián Martínez, pintor de cámara de Felipe IV." Senda de los Huertos: revista cultural de la provincia de Jaén, no. 21 (1991): 27-32.

Capel Margarito, Manuel. "Sebastián Martínez Domedel, discípulo de Velázquez y pintor de cámara de Felipe IV, en la Catedral de Jaén.” Boletín del Instituto de Estudios Giennenses, no. 67 (1971): 33-48.

---. "Pintura dispersa de Sebastián Martínez Domedel (1599-1667).” Boletín del Instituto de Estudios Giennenses, no. 78 (1973): 9-29.

---. Sebastián Martínez Domedel (1599-1667) y su escuela de pintores. Jaén: Colección Arte y artistas giennenses, 1999.

Galera Andreu, Pedro. "Pintores nobles y nobleza en la Jaén del Barroco." Cuadernos de Arte de la Universidad de Granada, no. 40 (2009): 193-208.

Galiano Puy, Rafael. "Catálogo de artistas y artesanos de la ciudad de Jaén (1634-1684) de Juan de Aranda Salazar a Eufrasio López Rojas (II).” Boletín de Estudios Giennenses, no. 205 (2012): 105-51.

Hall, James. Diccionario de temas y símbolos artísticos. Madrid: Alianza, 1987.

Hoffmann-Samland, Jens, coord. Dibujos españoles en la Kunsthalle de Hamburgo. Madrid: Museo Nacional del Prado, 2014.

Interián de Ayala, Juan. El pintor christiano, y erudito, ó Tratado de los errores que suelen cometerse freqüentemente en pintar, y esculpir las Imágenes Sagradas. Madrid: Joachín Ibarra, 1782.

Lázaro Damas, María Soledad. "Consideraciones en torno a Sebastián Martínez Domedel y su obra.” Boletín del Instituto de Estudios Giennenses 1, no. 153 (1994): 299-314.

León Coloma, Miguel Ángel. "Iconografía Barroca de San Ignacio de Loyola y San Francisco Javier. Notas a una exposición.” En La huella de los jesuitas en Granada. Del colegio de San Pablo a la Facultad de Teología, dirigido por Francisco Javier Martínez Medina, 153-208. Granada: Facultad de Teología, 2014.

Leonardi, Claudio, Andrea Riccardi, y Gabriella Zarri. Diccionario de los Santos. Madrid: San Pablo, 2000.

40. AHPJ: Protocolos Notariales, Carta de aceptación de Francisco Santo como aprendiz de Sebastián Martínez, 21 de marzo de 1640, legajo 1513, 133r-134v. Véase Lázaro Damas, "Consideraciones en torno," 304-5. 
Mantas Fernández, Rafael. "Claves estilísticas y formales en torno a la paleta de Sebastian Martínez.” En Barroco Iberoamericano: identidades culturales de un Imperio, coordinado por Carme López Calderón, María de los Ángeles Fernández Valle, y María Inmaculada Rodríguez Moya, 389-406. Santiago de Compostela: Andavira, 2013.

---. "Investigación y restauración: dos factores esenciales para la puesta en valor de la obra del pintor Sebvastián Martínez Domedel.” En Actas del XI Congreso Virtual Internacional Turismo y Desarrollo \& VII simposio virtual Internacional Valor y Sugestión del Patrimonio Artístico y Cultural (11 al 25 de julio de 2017), coordinado por Juan Carlos Martínez Coll, 609-30, Málaga: Universidad de Málaga, 2017.

Nancarrow, Mindy, y Benito Navarrete Prieto. Antonio del Castillo. Madrid: Fundación de Apoyo a la Historia del Arte Hispánico, 2004.

Navarrete Prieto, Benito, y Alfonso E. Pérez Sánchez. Álbum Alcubierre. Dibujos. De la Sevilla Ilustrada del Conde del Águila a la Colección Juan Abelló. Madrid: Fundación Arte Hispánico, 2009.

Navarrete Prieto, Benito. La pintura andaluza del siglo XVII y sus fuentes grabadas. Madrid: Gráficas Caro, 1998.

---. "Sebastián Martínez Domedel en el contexto de la pintura barroca andaluza." En Sebastianus. Pintor de Jaén. Sebastián Martínez Domedel (Jaén, 1615-Madrid, 1667), coordinado por Pedro A. Galera Andreu y Felipe Serrano Estrella, 17-58. Jaén: Diputación Provincial de Jaén e Instituto de Estudios Giennenses, 2016.

---. "Sebastián Martínez, nueva luz sobre su obra." Conferencia presentada en la Diputación Provincial de Jaén, Jaén, 27 de mayo de 2010.

Palencia Cerezo, José María, y Javier Del Campo. El esplendor del Barroco Andaluz. Colección Granados. Córdoba: Imprenta San Pablo, 2007.

---. Espiritu Barroco. Colección Granados. Burgos: Caja de Burgos, 2008.

Palencia Cerezo, José María. “Sebastián Martínez y el Apostolado del Palacio Episcopal de Córdoba.” En Actas del Congreso Internacional Andalucía Barroca (Antequera, 17-21 de septiembre de 2007), coordinado por Alfredo J. Morales, 373-84. Sevilla: Consejería de Cultura de la Junta de Andalucía, 2009.

---. “Sebastián Martínez, el gran desconocido.” Ars Magazine, no. 10 (2011): 102-14.

Palomino de Castro y Velasco, Antonio. Museo pictórico y escala óptica. Madrid: Aguilar, 1947.

Portús, Javier. "Sebastián Martínez (h. 1615-1667). San José con el Nińo (hacia 1650).” En Memoria de actividades 2009, 26-28. Madrid: Museo Nacional del Prado, 2010.

Quesada Quesada, José Joaquín. "Iconografía Franciscana en la provincia de Jaén. Del siglo XIII a la Desamortización de 1836.” Tesis doctoral, Universidad de Jaén, 2017.

Réau, Louis. Iconografía del Arte cristiano. 5 vols. Barcelona: Ediciones del Serval, 1996.

Serrano Estrella, Felipe, coord. Cien obras maestras de la Catedral de Jaén. Jaén: Universidad de Jaén y Cabildo de la S. I. Catedral de Jaén, 2012.

UNESCO. United Nations Educational, Scientific and Cultural Organization, "Monasterio de Poblet." Consultado el 25 de marzo de 2019. https://whc.unesco.org/es/list/518

Valdivieso, Enrique. Valdés Leal. Sevilla: Ediciones Guadalquivir, 1988. 